\title{
Availability and use of hemostatic agents in prehospital trauma patients in Pennsylvania translation from the military to the civilian setting
}

This article was published in the following Dove Press journal:

Open Access Emergency Medicine

6 July 2017

Number of times this article has been viewed

\author{
Adam Sigal' \\ Anthony Martin' \\ Adrian Ong ${ }^{2}$ \\ 'Department of Emergency Medicine, \\ ${ }^{2}$ Department of Surgery, Trauma \\ Section, The Reading Hospital, West \\ Reading, PA, USA
}

Objective: To understand the translation of one innovation in trauma care from the military to the civilian setting, the adoption of topical hemostatic agents in the Emergency Medical Services (EMS) community and in Trauma Centers in Pennsylvania.

Method: We utilized an anonymous electronic survey of EMS Agency Administrative Officers and Trauma Center Coordinators.

Results: We received responses from 23\% (93/402) Advanced Life Support and Air Medical agencies in the State. Of the EMS agencies that responded, $46.6 \%(61 / 131)$ stock hemostatic products, with 55.5\% (44/79) carrying QuickClot ${ }^{\circledR}$ Combat Gauze $^{\circledR}$. Of the agencies that carried hemostatic products, $50 \%$ utilized them at least once in the prior 6 months and $59 \%$ over the past 12 months. Despite the infrequent number of applications, prehospital providers ranked themselves as somewhat skilled and comfortable both with the application of the products and the indications for their use.

Conclusion: Our survey found that $46.6 \%$ of the respondents indicated they carry hemostatic products, a much greater number than found on prior surveys of EMS agencies. There is a steady acceptance by EMS of new innovations in trauma care although more work is needed in translating the exact role of hemostatic agents in the civilian setting.

Keywords: hemostatic, dressing, trauma, prehospital, trauma care, EMS

\section{Introduction}

Clinical knowledge, especially regarding care of the trauma patient, has often flowed between the civilian and military settings. The past decade's experience of combat care in Operation Enduring Freedom (Afghanistan) and in Operation Iraqi Freedom (Iraq) has seen a dramatic increase in the knowledge flow from the battlefield to the civilian setting. Tactical Combat Casualty Care has drastically changed the practice of combat medicine by training front-line personnel in advanced life-threatening treatments, including hemorrhage control. ${ }^{1,2}$ Early and frequent use of tourniquets and hemostatic agents are examples of innovations adopted by front-line troops and medics in controlling early hemorrhage. ${ }^{1,2}$ The US Military deployed first- and second-generation hemostatic dressings to combat troops in Iraq and Afghanistan after extensive investment in translational research. The type of agent deployed changed frequently during the ongoing operations from biologic agents containing blood products to chitin-based and then mineral-based products. Military researchers and manufacturers were able to fast-track development and United States Food and Drug Administration approval as many of the products were considered medical devices. ${ }^{3}$
Correspondence: Adam Sigal

Department of Emergency Medicine, The Reading Hospital, 6th Avenue and Spruce Streets, West Reading, PA I96II, USA Email adam.sigal@readinghealth.org 
The percent of combat casualties surviving from wounds suffered during combat in Iraq and Afghanistan was 90\%, an unprecedented level compared with casualties from Vietnam (84\%) and World War II (80\%). However, acute hemorrhage remains the leading cause of combat death. ${ }^{4}$ Hemostatic products were initially chosen based on animal model studies and revised after real-world combat experience. The initial studies were designed to test the safety and efficacy of the products. Adoption of early agents was based on studies with animal models and subsequent case reports have confirmed their utility under combat conditions. ${ }^{5}$

The American College of Surgeons (ACS) Committee on Trauma released an evidence-based guideline on the use of hemostatic agents. The ACS recommended that topical hemostatic agents be used "in combination with direct pressure, for the control of significant hemorrhage in the prehospital setting in anatomic areas where tourniquets cannot be applied and where sustained direct pressure alone is ineffective or impractical." The agents should be "delivered in a gauze format that supports wound packing." "The recommendations were based on both prehospital studies in the military and civilian setting as well as animal studies. As there was a paucity of human studies, the strength of this recommendation was categorized as "low" and the quality of evidence as "weak".

In this study, we aimed to understand the translation of one innovation in trauma care from the military to the civilian setting, the adoption of topical hemostatic agents in the Emergency Medical Services (EMS) community on a statewide level. Our hypothesis is that the majority of civilian EMS agencies in Pennsylvania have adopted hemostatic agents in the care of trauma patients.

\section{Methods}

We surveyed all EMS agencies in the Commonwealth of Pennsylvania utilizing contact information from the
Pennsylvania Emergency Health Services Council, an independent advisory body to the Pennsylvania Department of Health. ${ }^{7}$ We also surveyed accredited Pennsylvania Trauma Centers utilizing contact information from the Pennsylvania Trauma Systems Foundation, the accrediting body for trauma centers throughout the Commonwealth of Pennsylvania. ${ }^{8}$ We sent one survey to the Administration Officer of each licensed EMS agency and one to the Trauma Coordinator of each designated Trauma Center (levels I-IV). We used Survey Monkey (Palo Alto, CA, USA) to conduct the inquiries in an anonymous manner (Table 1). We used a 1-7 Likert-type scale to understand the respondents' skill in using hemostatic products and their comfort in the indications for their use, with 1 being least skilled or comfortable and 7 being extremely skilled or comfortable. The survey was conducted from April 15, 2016 to May 30, 2016.

The Reading Health System Institutional Review Board (IRB) reviewed the study and determined it met the requirement for exemption from IRB review found in the Code of Federal Regulations, Title 45, Part 46, Section 101(b)(2). This determination was based on the following: the research is found to be of minimal risk, the research involves the use of survey procedures in which the information obtained is not recorded in such a manner that human subjects can be identified, and any disclosure of the subjects' responses outside the research will not reasonably place them at risk of criminal or civil liability or be damaging to their financial standing, employability or reputation. Informed consent to participate was obtained with the first question of the survey. If participants did not want to respond to the survey, the questions ended.

\section{Results EMS agencies}

The responding agencies represented nearly every region of the state including urban, suburban, and rural environments.

Table I Questionnaire for Emergency Medical Services (EMS) and Trauma Centers

\begin{tabular}{|c|c|}
\hline Questions for EMS agencies & Questions for Trauma Centers \\
\hline In which regional council are you located? & In which county are you located? \\
\hline What is the highest level of service for which the agency is licensed? & What is the Hospital's Trauma Level designation? \\
\hline Does the agency stock hemostatic products? Which impregnated gauze & Does the Trauma Center carry hemostatic products? Which \\
\hline product is your agency trained and authorized to carry? & impregnated gauze products are stocked by the facility? \\
\hline How often has your EMS agency used hemostatic products over the last & How often has the facility received patients with hemostatic agents \\
\hline 6 months? Over the past 12 months? & applied prehospital over the past 6 months? Over the past 12 months? \\
\hline How many training hours on the use of hemostatic products has your & How often has the trauma team used hemostatic agents in the Trauma \\
\hline EMS agency provided over the past 12 months? & Bay over the past 6 months? Over the past 12 months? \\
\hline $\begin{array}{l}\text { Rate the skill and comfort levels of the practitioners in your EMS agency } \\
\text { regarding the indications for and utilization of hemostatic agents }\end{array}$ & $\begin{array}{l}\text { Rate the skill and comfort level of trauma team in utilizing hemostatic } \\
\text { agents }\end{array}$ \\
\hline
\end{tabular}


Respondents represented 12 of the 14 Regional EMS Councils. We received responses from $23 \%(89 / 387)$ of all Advanced Life Support agencies in the state and 26.6\% (4/15) of Air Medical units. Only 3.87\% (39/1007) of the Basic Life Support/Quick Response Service agencies responded to the survey. Ten respondents did not indicate their level of service. Fifty-three percent of those who responded to question 3 (70/131 with 11 not answering) indicated that they did not carry any hemostatic agent; but of those agencies that did stock hemostatic agents, the majority used QuikClot ${ }^{\mathbb{R}}$ Combat Gauze ${ }^{\circledR}$ (Figure 1) with 14 agencies carrying more than one product.

Of the 61 respondents who indicated they carry hemostatic agents, $59 \%(36 / 61)$ used them at least once in the prior 6 months and $68.85 \%(42 / 61)$ at least once over the past 12 months of the survey (Figure 2). Although 61 agencies carry hemostatic product, 84 agencies indicated that they have provided at least 1 hour of education on their use.

Using a Likert-type scale of 1-7, EMS providers scored a median of 4.0 (interquartile range [IQR] of 2-6) on skill in the application of hemostatic products and a median of 4 (IQR of 3-6) in rating their comfort level in the indications for using hemostatic products. The scores indicated that the majority of respondents scored themselves at or greater than just somewhat skilled and comfortable in using hemostatic products.

\section{Trauma Centers}

Twenty-two of the 36 (61.1\%) designated Trauma Centers responded to the survey with a broad distribution throughout the counties. The majority of the respondents were level I designated (6) and level II designated (5) with eight centers not answering the question. Although half of the respondents did not answer which hemostatic agents were stocked by their facility, for those that carried any agents, most carried QuikClot Combat Gauze (Figure 1). Two hospitals carried more than one product.

Trauma Centers indicated that EMS infrequently transported patients with hemostatic product applied in the prehospital setting. Three centers had received only one patient

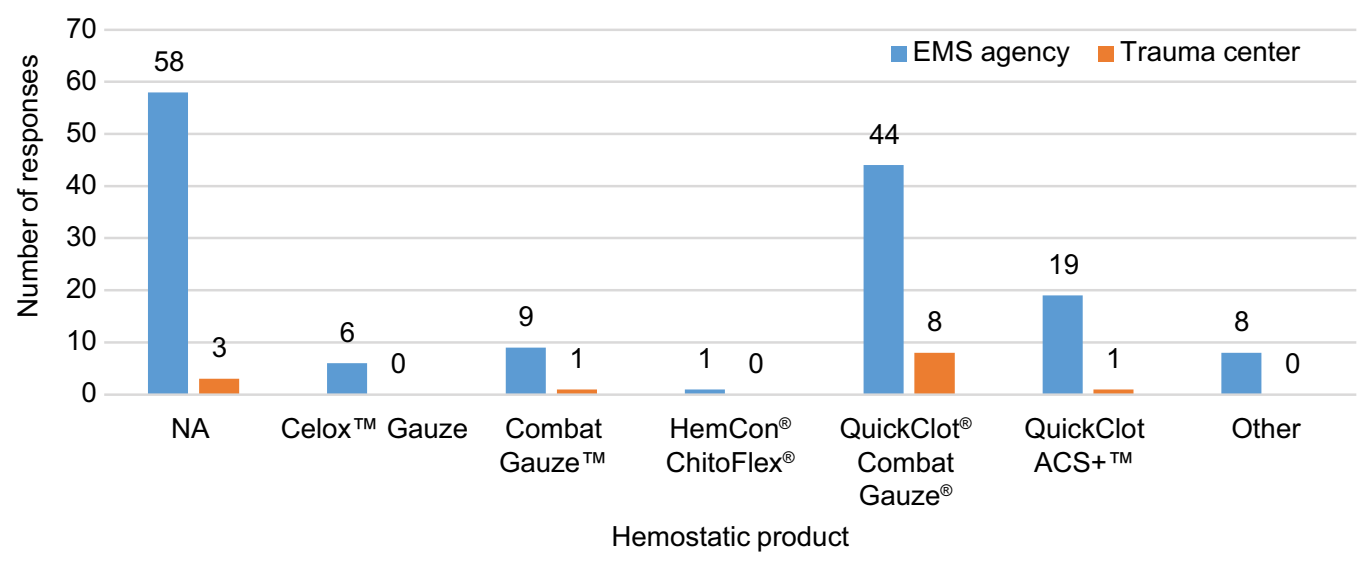

Figure I Which of the following impregnated gauze products does your agency or Trauma Center carry? Abbreviation: EMS, Emergency Medical Services.

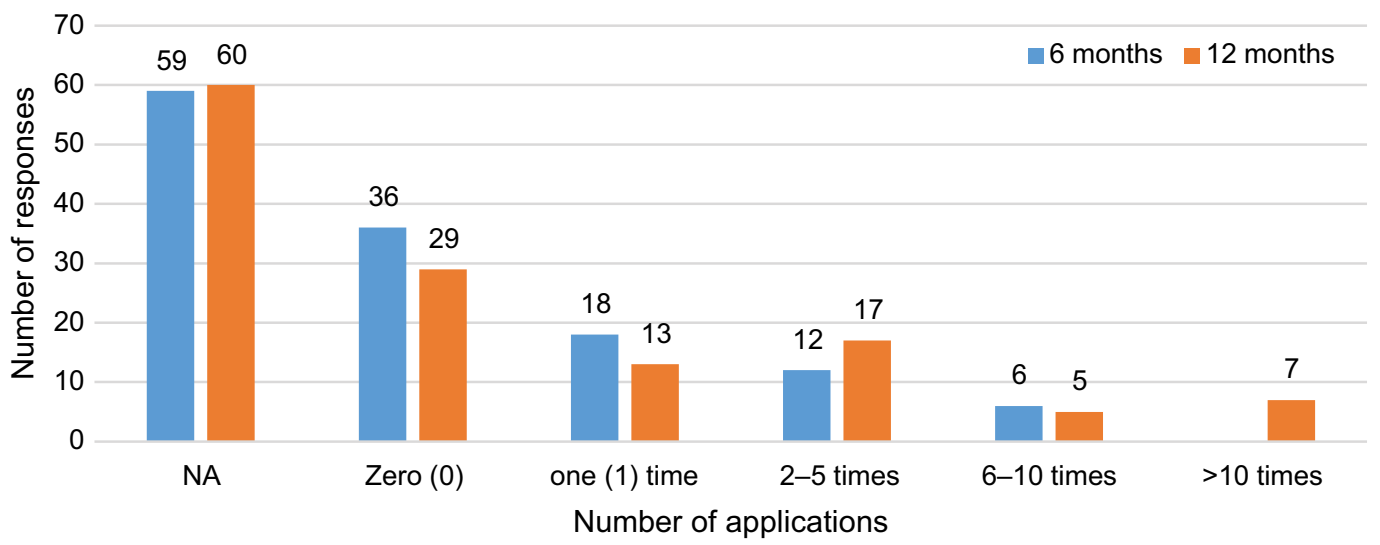

Figure 2 How often has your EMS agency used hemostatic products? Abbreviations: NA, not applicable; EMS, Emergency Medical Services. 
in the prior 6 months and one had received $2-5$ patients in the prior 6 months. Four of these centers received $2-5$ patients and one center received $>10$ patients in the preceding 12 months. Nine Trauma Centers indicated that they had never received patients with prehospital applied hemostatic product over the past 12 months with eight centers not answering the question.

The primary application of these products in the Emergency Department by the Trauma team was also infrequent. Over the prior 6 months, two centers had each applied the agents once and five had each applied the product two to five times. Over the past 12 months, three centers each had applied the products $2-5$ times, three had each applied the products 6-10 times, and two had each applied the products $>10$ times. Compared to EMS providers, Trauma Centers scored a median of 6.0 (IQR 1-7) in application skills and a median of 6.0 (IQR 1-7) in comfort in the indications for using hemostatic agent based on a Likert-type scale of 1-7. Trauma Centers scored EMS providers with a median of 4 (IQR 1-6) for skill and a median of 4 (IQR 1-6) in comfort with indication for hemostatic agents.

\section{Discussion}

Many of the initial studies on hemostatic agents consisted of laboratory studies and animal models. The recent combat in Iraq and Afghanistan provided retrospective observational studies on their utility in combat environments. ${ }^{3,9}$ The literature has few studies indicating how best to translate the experience of these agents to the civilian world. Galante et al surveyed 31 EMS agencies in California and found that only $7 \%$ of respondents currently deployed hemostatic agents with questions regarding their benefit in the civilian setting, complications with use, and cost being the most widely cited barriers to increased utilization. ${ }^{10}$ Agencies were more likely to deploy and utilize tourniquets than hemostatic agents. Among law enforcement personnel, 34\% and 29.8\% of respondents in a nationwide survey by Aberle et al reported their departments issuing tourniquets and hemostatic agents, respectively. ${ }^{11}$ As expected, agencies deploying these products also were more likely to conduct training on their use. ${ }^{11}$

The Israeli Defense Force also had success in incorporating these agents in the care of combat casualties. ${ }^{12}$ There have been only a few studies reviewing the use of hemostatic agents in the civilian setting. The prior studies conducted under austere combat conditions may not translate to the civilian setting. These conditions include needing to care for patients during combat, delay in evacuation to a treatment facility, and first treatment facility not being a tertiary facil- ity. ${ }^{13}$ Brown et al conducted a retrospective chart review on 37 uses in a civilian setting by EMS providers after receiving training on the product and its deployment. ${ }^{14}$ They noted that an overall success rate in controlling bleeding was $79 \%$. This study had a small number of patients and the authors note that the infrequency of application may play a role in maintaining prehospital provider proficiency. The study also used a Hem Con dressing. Recently, the Tactical Combat Casualty Care Guidelines have recommended using Combat Gauze as a first-line agent to control significant bleeding. ${ }^{14,15}$ Hatamabadi et al performed a prospective randomized trial of traditional direct pressure versus a Celox-coated gauze in managing bleeding in civilian stab wounds. ${ }^{16}$ Their results demonstrated that hemostasis was achieved earlier and blood loss was significantly less with the use of a hemostatic agent. ${ }^{16}$ The literature has few studies indicating how best to translate the experience of these agents to the civilian world. The few studies that do exist utilized agents no longer recommended by the Committee on Tactical Combat Casualty Care. ${ }^{17}$ On the basis of recent studies by te Grotenhuis et al and Leonard et al, hemostatic agents seem to be efficacious in adjunctive control of bleeding in the prehospital civilian setting. The total number of applications of hemostatic gauze in both studies was small, however. ${ }^{18,19}$

Zietlow et al reported on their experience with hemostatic agents and tourniquet use in a single rural ground and rotorwing medical transport service. Out of 203,301 ground ambulance and 8,987 air transport records, 73 patients were treated with 77 tourniquets and 62 hemostatic dressings were applied to 52 patients, with 7 patients requiring both interventions. The number of patients treated with either or both modalities was 125 , which constitutes $\sim 0.06 \%$ of all transport records in that period. Hemostatic dressings were only applied when ordinary dressing was unsuccessful in arresting hemorrhage according to their protocol. The success rate of hemostatic dressings in stopping hemorrhage was $95 \%$ in this cohort. The authors specifically mentioned that hemostatic dressings would be useful in hemodialysis patients with fistula bleeding. In their units, the 2-year proficiency rate was $98 \% .^{20}$

Our study showed that a substantial proportion of Pennsylvania EMS agencies (46.56\% of respondents) had added hemostatic agents to their hemorrhage control armamentarium when compared with a recent survey of EMS agencies. ${ }^{10}$ A similar percentage of Trauma Centers are currently stocking the agents but less than half of the respondents have utilized the agents at least once over the past 12 months. Although half the EMS agencies that carry the products have used them over the past year, the actual number of applica- 
tions is small when compared with Pennsylvania statewide 2013 statistics on motor vehicle injuries $(10,399)$, selfinflicted injuries $(9,172)$, and injuries from assault $(4,341)$ or all injuries requiring hospitalizations $(132,614) .{ }^{21}$ The low utilization mirrors the experience in the tri-state area of Iowa, Minnesota, and Wisconsin. ${ }^{20}$

There is only a small discrepancy between EMS providers, self-reported skill level and comfort with the indications for the use of hemostatic agents and Trauma Center evaluation of prehospital care. On the basis of Galante et al's findings, we assume that most of the EMS agencies conducting training on the agents are those that have decided to stock them for use. Some agencies are providing many more hours than others, and this may reflect their real-world experience. ${ }^{10}$ Galante et al also pointed out that although only $7 \%$ of respondents in their study were using hemostatic agents, 39\% felt that there was a role in civilian EMS agencies.

This study showed that although EMS units are proficient in the use of hemostatic agents, the rate of usage is still low. Although Zietlow et al evaluated the two dominant prehospital units in a tri-state rural setting, our study aimed to provide insight into the availability, self-perception of proficiency among EMS providers, and extent of the use of these agents in a state with multiple EMS agencies. ${ }^{20}$ Our findings are likely limited by reporting bias, as $<30 \%$ of all Advanced Life Support and Air Medical units responded. Out of those who reported, only $47 \%$ stocked hemostatic agents. This might suggest that although there is increasing acceptance of these agents in the prehospital setting, educational efforts might still be important in promoting usage and familiarity about these agents.

Recently the Committee for Tactical Emergency Casualty Care and the Hartford Consensus IV (HC IV) have provided the framework for translating knowledge obtained from combat care to the civilian setting, especially in high threat scenarios. Central to the vision of the HC IV is educating the lay public to act as immediate responders in arresting hemorrhage until trained professionals arrive. It is envisioned that immediate responders be familiar with hemorrhage control equipment, such as tourniquets and hemostatic dressings. As our survey found that less than half of responding professional EMS agencies in a mature statewide trauma system stock hemostatic dressings, it is important to address this finding if these agents are going to be widely available to the lay public..$^{22,23}$

\section{Conclusion}

There is a lag in translating the military experience with hemostatic dressings to the civilian setting. It is not clear whether the low utilization rates are due to lack of clinical indications for the agents, lack of availability in the EMS Agencies, or lack of comfort with using the product. Future research is needed in the civilian environment to develop training programs and to describe the appropriate role of hemostatic agents with other adjuvants of hemostatic control: elevation, direct pressure, and tourniquets. Addressing any impediments to use in the professional EMS community will be important prior to meeting the $\mathrm{HC}$ goals of training immediate responders.

\section{Disclosure}

The authors report no conflicts of interest in this work.

\section{References}

1. Elster E, Schoomaker E, Rice C. The laboratory of war: how military trauma care advances are benefiting soldiers and civilians [Blog post]. Available from: http:/healthaffairs.org/blog/2013/12/18/the-laboratoryof-war-how-military-trauma-care-advances-are-benefiting-soldiersand-civilians/. Accessed December 18, 2013.

2. Blackbourne LH, Baer DG, Eastridge BJ, et al. Military medical revolution: prehospital combat casualty care. J Trauma Acute Care Surg. 2012;73(6 Suppl 5):S372-S377.

3. Kheirabadi B. Evaluation of topical hemostatic agents of combat wound treatment. US Army Med Dep J. 2011:25-37.

4. Easridge BJ, Mabry RL, Seguin P, et al. Death on the battlefield (2001-2011): implications for the future of combat casualty care. J Trauma Acute Care Surg. 2012;73(6 Suppl 5):S431-S437.

5. Bennet BL, Littlejohn LF, Kheirabadi BS, et al. Management of external hemorrhage in tactical combat casualty care: chitosan-based hemostatic gauze dressings. J Spec Oper Med. 2014;14(3):40-57.

6. Bulger EM, Snyder D, Schoelles, K, et al. An evidence-based prehospital guideline for external hemorrhage control: American College of Surgeons Committee on Trauma. Prehosp Emerg Care. 2014:18(2);163-173.

7. Mission/Vision. Pennsylvania Emergency Health Services Council website. Available from: http://pehsc.org/about-us/missionvision/. Accessed June 7, 2016.

8. Altenburg J. Who is PTSF? Pennsylvania Trauma Systems Foundation website. Available from: http://www.ptsf.org/index.php/about-us Accessed June 7, 2016.

9. Wedmore I, McManus JG, Pusateri AE, Holcomb JB. A special report on the chitosan-based hemostatic dressing: experience in the current combat operations. J Trauma. 2006;60(3):655-658.

10. Galante JM, Smith CA, Sena MJ, Scherer LA, Tharratt RS. Identification of barriers to adaptation of battlefield technologies into civilian trauma in California. Mil Med. 2013:178(11);1227-1230.

11. Aberle SJ, Dennis AJ, Landry JM, Sztajnkrycer MD. Hemorrhage control by law enforcement personnel: a survey of knowledge translation from the military combat experience. Mil Med. 2015:180(6);615-620.

12. Ran Y, Hadad E, Daher S, et al. Quikclot combat gauze use for hemorrhage control in military trauma: January 2009 Israel defense force experience in the Gaza Strip - a preliminary report of 14 cases. Prehosp Disaster Med. 2010;25(6):584-588.

13. Gordy SD, Rhee P, Schreiber MA. Military applications of novel hemostatic devices. Expert Rev Med Devices. 2011;8(1):41-47.

14. Brown MA, Daya MR, Worley JA. Experience with chitosan dressings in a civilian EMS system. J Emerg Med. 2009;37(1):1-7.

15. Prehospital Trauma Life Support Committee of the National Association of Emergency Medicine Technicians, \& Committee on Trauma of the American College of Surgeons. Pre-Hospital Trauma Life Support. 8th ed. Burlington, MA: Jones and Bartlett Learning; 2016.

16. Hatamabadi HR, Zarchi FA, Kariman H, Dolatabadi AA, Tabatabaey A, Amini A. Celox-coated gauze for the treatment of civilian penetrating trauma: a randomized clinical trial. Trauma Mon. 2015;20(1):1-5. 
17. TCCC Guidelines. CoTCCC website. Available from: http://www.naemt. org/education/TCCC/guidelines_curriculum. Accessed June 7, 2016.

18. Te Grotenhuis R, van Grunsven PM, Heutz WM, Tan EC. Prehospital use of hemostatic dressings in emergency medical services in the Netherlands: a prospective study of 66 cases. Injury. 2016;47(5):1007-1011.

19. Leonard J, Zietlow J, Morris D, et al. A multi-institutional study of hemostatic gauze and tourniquets in rural civilian trauma. J Trauma Acute Care Surg. 2016;81(3):441-444.

20. Zietlow JM, Zietlow SP, Morris DS, Berns KS, Jenkins DH. Prehospital use of hemostatic bandages and tourniquets: translation from military experience to implementation in civilian trauma care. J Spec Oper Med. 2015;15(2):48-53.
21. Injury Deaths and Hospitalizations in Pennsylvania; 2009-2013. Pennsylvania Health Statistics website. Available from: http:/www.statistics. health.pa.gov/HealthStatistics/BehavioralStatistics/InjuryStatistics/ Pages/InjuryStatistics.aspx\#.V1cRzYLD_Co. Accessed June 7, 2016

22. Jacobs LM; Joint Committee to Create a National Policy to Enhance Survivability from Intentional Mass Casualty and Active Shooter Events. The Hartford consensus IV: a call for increased national resilience. Bull Am Coll Surg. 2016;101(3):17-24.

23. Callaway DW. Translating tactical combat casualty care lessons learned to the high-threat civilian setting: tactical emergency casualty care and the Hartford consensus. Wilderness Environ Med. 2017. Accessed June $12,2017$.
Open Access Emergency Medicine

\section{Publish your work in this journal}

The Open Access Emergency Medicine is an international, peerreviewed, open access journal publishing original research, reports, editorials, reviews and commentaries on all aspects of emergency medicine. The manuscript management system is completely online and includes a very quick and fair peer-review system, which is all

\section{Dovepress}

easy to use. Visit http://www.dovepress.com/testimonials.php to read real quotes from published authors. 